\title{
Exercise and Upper Respiratory Tract Infections
}

\section{Is There a Relationship?}

\author{
Gregory W. Heath, Caroline A. Macera and David C. Nieman \\ Division of Chronic Disease Control and Community Intervention, \\ Centers for Disease Control, Atlanta, Georgia, Department of Epidemiology and Biostatistics, \\ School of Public Health, University of South Carolina, Columbia, South Carolina, and \\ Department of Health, Leisure, and Exercise Science, Appalachian State University, \\ Boone, North Carolina, USA
}

Runners and other exercise enthusiasts are traditionally motivated to participate in sports for competitive or recreational reasons. However, some exercise participants are convinced that exercise will provide health benefits (Nash 1986). Indeed, regular exercise and physical activity have been established as a means of reducing cardiovascular disease risk and contributing to longevity (Paffenbarger et al. 1986; Powell et al. 1987). In addition, habitual exercisers often report other health-related rewards from endurance exercise such as weight control (Heath et al. 1981), improved energy levels (Hughes 1984) and stress reduction (Blumenthal et al. 1980; Sinyor et al. 1983). Many exercisers also believe that exercise improves their resistance to infection and anecdotally report that they have fewer colds and other upper respiratory tract infections (URTI) [Simon 1987]. Despite these beliefs, few studies have examined the relationships that exist among exercise and clinical expressions of upper respiratory tract infections. This article seeks to examine the existing studies that have investigated the relationship between exercise and upper respiratory tract infections and to determine if any such relationship exists. It begins by defining and discussing the specific health outcome of infections and the classification of these diseases. Secondly, the epidemiology and natural history are discussed with the clinical and experimental evi- dence of the relationship between upper respiratory tract infections and exercise explored. The suggested immunological and physiological mechanisms of this possible relationship are examined, followed by a review of the epidemiological data linking an association of exercise to upper respiratory tract infections. Finally, guidelines for the exercising public are presented as an application of our attempt to answer the question: exercise and upper respiratory tract infections - is there a relationship?

\section{Classification and Definitions of Upper Respiratory Tract Infections}

Upper respiratory tract infections consist of a number of acute illnesses that occur in the upper portion of the respiratory tract. The most common infections include pharyngitis, croup, bacterial tracheitis, epiglottitis and the common cold. Since the common cold is the leading acute illness and cause of visits to a physician in the developed world, the common cold is a focus of the article. The term 'cold' carries different meanings for many people; however, it is usually defined as an acute illness that involves nasopharyngitis and catarrh, little or no fever and insignificant systemic symptoms. 
Table I. Viruses associated with the common cold (Hall \& McBride 1989)

\begin{tabular}{|c|c|}
\hline Virus & Predominant seasons \\
\hline \multicolumn{2}{|l|}{ Most common } \\
\hline Rhinoviruses & $\begin{array}{l}\text { Autumn, mid-spring } \\
\text { to summer }\end{array}$ \\
\hline Coronaviruses & Winter \\
\hline \multicolumn{2}{|l|}{ Common } \\
\hline Parainfluenza viruses & Autumn, spring \\
\hline Respiratory syncytial virus & Winter to early spring \\
\hline Influenza viruses & Winter \\
\hline \multicolumn{2}{|l|}{ Less common } \\
\hline Adenoviruses & All seasons \\
\hline Enteroviruses & Summer, autumn \\
\hline Reoviruses & All seasons \\
\hline
\end{tabular}

\subsection{Aetiology}

The aetiology of this group of upper respiratory tract infections is viral in nature. The predominant group of viruses which cause colds are the rhinoviruses followed by the coronaviruses (table I). The parainfluenza viruses, respiratory syncytial virus and influenza viruses are all epidemic viruses that are associated with colds. However, these viruses cause more serious upper respiratory tract infections which tend to mask the milder colds (Hall \& McBride 1989).

\subsection{Pathophysiology}

Transmission of upper respiratory tract infection-causing viruses may occur through several modes. Suspension of viral particles in large droplets produced by a cough or sneeze with direct contact into the eyes or on to the upper respiratory passages is a common mode, usually produced by close contact with the infected individual. Virus suspended in the small particle aerosol of a sneeze or cough is capable of travelling greater distances and is another common mode of infection. Finally, the virus can be spread by contact with contaminated secretions by hand from contaminated surface to mucous membranes (self-inoculation) [Hall \& McBride 1989]. For most of the respiratory vi- ruses it is not known which of these modes of spread are most important. For rhinovirus and respiratory syncytial virus close contact with an infected person or infected secretions is necessary, with a number of studies demonstrating that people infected with rhinovirus colds have recoverable infectious virus on their hands (Gwaltney 1983; Gwaltney \& Hendley 1978; Hendley et al. 1973). Furthermore, these studies have shown that rhinovirus may be readily transferred from the contaminated hands of one person to the hands of another who, if susceptible, may acquire infection by touching his nasal or conjunctival mucosa.

\subsection{Epidemiology Of and Risk Factors For Upper Respiratory Tract Infections}

When examining the numbers and types of viruses causing upper respiratory tract infections it is clear that this is a rather ubiquitous group of infections. In general, the number of infections acquired per year decreases with age (Bader et al. 1953; Brimblecombe et al. 1958; Dingle et al. 1964; Fox et al. 1972; Gwaltney et al. 1966). Infants and children have the highest incidence with 4 to 8 infections per year. This rate may even double when children are in day care or nursery school. In schoolaged children the incidence is 2 to 6 colds per year (Badger et al. 1953; Brimblecombe et al. 1958; Dingle et al. 1964; Fox et al. 1972). Adults acquire 2 to 5 upper respiratory tract infections per year, with women and adults who live in households with children tending to suffer even more colds per year (Gwaltney et al. 1966). Smoking has been shown to aggravate the signs and symptoms of infection but not to increase the attack rate (Gwaltney et al. 1966, 1967). Exposure to cold or to chilling does not increase the chance of acquiring or aggravating a cold (Douglas et al. 1968). Recent studies have demonstrated that psychological stress is a risk factor for the development of an upper respiratory tract infection (Cohen et al. 1991; Graham 1986). Finally, in studies exploring the prophylactic use of vitamin $C$ in prevention, the attack rate of upper respiratory tract infections was not diminished al- 
though symptoms were ameliorated (Coulehan et al. 1976; Karlowski et al. 1975; Miller et al. 1977).

\section{Clinical and Experimental Evidence}

Human and animal experimental evidence has demonstrated a relationship between exercise and upper respiratory tract infections (Nieman \& Nehlsen-Cannarella 1991a, 1992). Furthermore, these studies provide insight into potential mechanisms that might explain the relationship between physical activity and infection.

\subsection{Immune Response to Heavy Exertion $\left(>70 \% \dot{V}_{2 \max }\right)$}

Several researchers have reported that various aspects of immune function are depressed following intense, prolonged endurance exercise (Nieman \& Nehlsen-Cannarella 1991a). Heavy exertion is a form of physiological stress that causes large increases in epinephrine (adrenaline) and cortisol levels, hormones which have been consistently associated with a suppression of immune function, and rapid perturbations in circulating levels of leucocyte and lymphocyte subsets.

Nieman et al. (1989a) and Berk et al. (1990) ran 10 seasoned marathoners at their fastest marathon pace on treadmills for 3 hours. Cortisol rose $59 \%$ above baseline levels after the 3-hour run, remain-

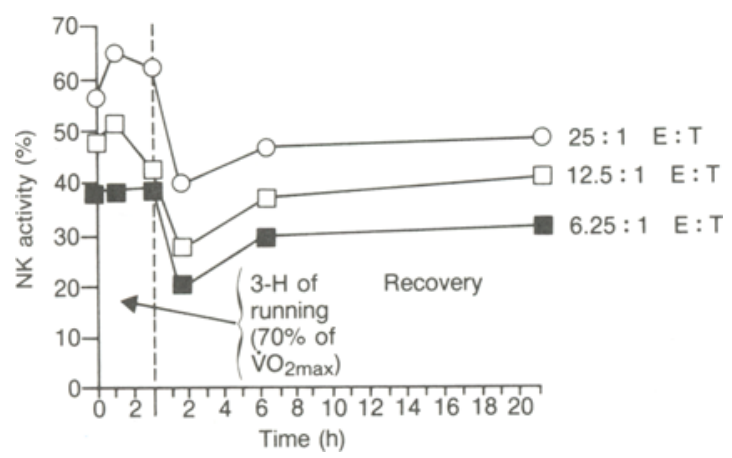

Fig. 1. The changes in natural killer (NK) cell activity at 3 effector : target $(\mathrm{E}: \mathrm{T})$ ratios at $1.5,6$ and $21 \mathrm{~h}$ following a $3 \mathrm{~h}$ run at $70 \% \mathrm{vO}_{2 \max }$.

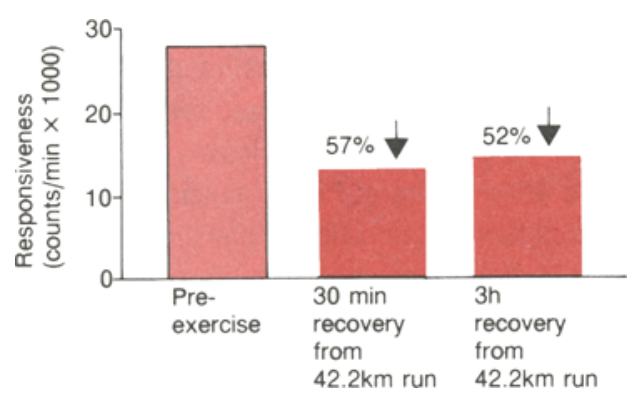

Fig. 2. Effect of marathon running on lymphocyte responsiveness to concanavalin $\mathrm{A}(\mathrm{Con} \mathrm{A})$ at pre-exercise and at 30 min and $3 \mathrm{~h}$ recovery from the marathon.

ing elevated for 1.5 hours of recovery before falling to normal daytime levels. This increase in cortisol correlated inversely with a 25 to $46 \%$ decrease in natural killer (NK) cell activity at 1.5 hours after recovery, which persisted for nearly 6 hours (fig. 1). Pedersen et al. $(1988,1989,1990)$ and Kappel et al. (1991) have carefully demonstrated that the post exercise suppression of natural killer cell activity is also related to increased levels of prostaglandins released from monocytes.

Eskola et al. (1978) and Gmunder et al. (1988) have reported a significant decrease in lymphocyte proliferative response for several hours after a marathon (42.2km) [fig. 2]. MacNeil et al. (1991) have demonstrated that the lymphocyte proliferative response is decreased for at least 2 hours following cycle ergometer exercise, especially following high intensity exercise by athletes. Following 1 hour of cycling at $80 \% \dot{\mathrm{VO}}_{2 \max }$ by untrained individuals, Tvede et al. (1989) found suppression of B lymphocyte function for at least 2 hours because of an inhibitory effect of activated monocytes. Smith et al. (1990) have determined that neutrophil killing capacity is decreased in elite athletes engaging in prolonged periods of intensive training in comparison to untrained controls.

Nieman et al. (1989b) and Smith et al. (1990) have reported significantly lower serum complement in long distance runners relative to sedentary controls. A significant decrease in salivary immunoglobulin concentrations following 2 hours of intense cycling or $50 \mathrm{~km}$ of cross-country ski racing 
has been described by 2 groups of investigators (Mackinnon et al. 1987; Tomasi et al. 1982). Israel et al. (1982) have reported that serum immunoglobulins fall 10 to $28 \%$ for at least 1 day after athletes run 45 or $75 \mathrm{~km}$ at high intensity. Russian investigators have related that exhaustion of immune reserves can be observed during periods of important competitions, manifested by lowered immunoglobulin levels and suppression of phagocytic activity of neutrophils (Pershin et al. 1985; Petrova et al. 1983, 1985).

Results from animal studies have rather consistently supported the view that heavy acute and chronic exertion are related to negative changes in immune function. Several researchers have reported that exhaustive single bouts of exercise by both trained and untrained animals, or 6 days to 4.5 months of heavy exercise training, are linked to increased splenic epinephrine and cortisol levels and decreased splenic natural killer and $T$ cell lymphocyte function (Ferry et al. 1990; HoffmanGoetz et al. 1986; Mahan \& Young 1989; Simpson \& Hoffman-Goetz 1990). Thus, both circulating immune cells and those found in secondary lymphoid tissues may have their function suppressed because of the increase in cortisol and catecholamine levels that occur following heavy exertion.

Further research is needed to better elucidate the clinical significance of exercise induced changes in immune status and function (many of which are transient in nature), and which variables best predict potential changes in host protection. The data at present are not consistent enough between studies to even suggest thresholds for various immune system markers that may indicate increased risk of upper respiratory tract infection.

\subsection{Contributing Effects of \\ Psychological Stress}

Psychological factors may also play an important role in the relationship between exercise and upper respiratory tract infection. Exercise is a form of physiological and psychological stress, varying according to the intensity and duration of the training programme. Interestingly, the acute re- sponse of the immune system to psychological stressors alone is in many ways similar to those that occur in response to acute exercise (Naliboff et al. 1991). If the exercise training programme is deemed stressful by the athlete, the combined psychological and physiological impact may overwhelm the ability of the immune system to protect the host (Nieman \& Nehlsen-Cannarella 1992). Mental stress alone has been related to a wide variety of negative changes in immunity. Bereavement, major depression, loneliness, schizophrenia, marital discord and other forms of mental stress have all been associated with suppression of immune function (Jemmott \& Locke 1984; Khansari et al. 1990).

A biochemical basis for bidirectional communication between the immune system and neuroendocrine system has been established (Blalock 1989). These systems produce and use many of the same signal molecules in the form of hormones, lymphokines and monokines for inter- and intrasystem communication and regulation. Lymphoid organs are innervated by the autonomic nervous system, and lymphocytes have receptors for the various stress hormones. In the other direction, for example, products of leucocytes have been shown to alter neuronal activity in certain areas of the brain.

Thus, stress of any form may decrease host protection from infection through both autonomic nervous system and hormonal mechanisms. Research by Graham and associates (1986), for example, has demonstrated that during a given 6month period, highly stressed individuals have twice as many days with respiratory infection symptoms compared with low-stressed people. Cohen et al. (1991) gave nasal drops containing respiratory viruses to 394 subjects and reported that psychological stress was associated in a dose-response manner with an increased risk of acute infectious respiratory illness. Although specific research in this area has not yet been conducted, it would seem logical to assume that athletes around the time of competition, when both physiological and psychological stress are high, would be most vulnerable to respiratory infections. 


\subsection{The Acute Phase Response}

Another factor that may be important for the risk of respiratory infection in athletes is the involvement of the immune system in the tissue repair process that occurs following strenuous exercise (for a review see Neiman \& Nehlsen-Cannarella 1991b). It has been well established that both heavy acute and chronic exertion are associated with muscle cell damage, local inflammation and the stereotyped sequence of host defence reactions known as the acute phase response (Evans \& Cannon 1991; Nieman \& Nehlsen-Cannarella 1991a).

The acute phase response following endurance exercise involves the complement system, neutrophils, macrophages, various cytokines and acute phase proteins, and can last for several days, promoting clearance of damaged tissue and setting the stage for repair and growth. Lymphocytes, neutrophils and macrophages are attracted to the injured muscle cells, and invade the area to aid in the process. Neutrophils phagocytise tissue debris and release a wide variety of factors that aid in the digestion of adjacent dead tissue cells (Smith 1991). Macrophages have surface receptors which allow them to react nonspecifically to a variety of substances, a process enhanced by the presence of opsonins (primarily complement and antibody). Macrophages also are a prime source of cytokines that mediate most of the physiological and inflammatory reactions accompanying muscle cell injury. Dufaux and Order (1989b) have shown that plasma elastase- $\alpha_{1}$-antitrypsin, neopterin, tumour necrosis factor and soluble interleukin-2 receptor increase during recovery from a 2.5-hour running test, supporting the concept of a functional involvement of polymorphonuclear neutrophils and an activation of macrophages and T-lymphocytes. Dufaux and Order (1989a) have also provided evidence for complement activation after 2.5 hours of running.

Could the active enmeshment of the immune system in the muscle tissue repair and inflammation process mean that protection from respiratory infection is compromised? Research to answer this question is certainly warranted, and may greatly increase our understanding as to how and why ath- letes appear to be more susceptible to respiratory tract infections during periods of heavy training.

\subsection{Immune Response to Moderate Exertion $\left(\leqslant 70 \% \dot{\vee V}_{2 \max }\right)$}

Few studies have investigated the common belief that moderate physical activity is beneficial in decreasing risk of respiratory tract infections and improving immune function. More research is certainly warranted to investigate this interesting area.

Since the turn of the century, the influence of exercise training on resistance to infection has been investigated using animal models. Cannon and Kluger (1984) have reviewed the animal literature and concluded that moderate exercise prior to infection may increase resistance to infection, but that exhaustive exercise after contracting an infection may be detrimental. In accordance with this viewpoint, Slubik et al. (1987) have reported that moderate physical exercise preceding irradiation diminishes radiation injury in animals while intensive exercise and stress may aggravate the damage.

Smith et al. (1990) have shown that 1 hour of cycling at $60 \% \dot{\mathrm{V}}_{2 \max }$ may increase resistance to infection by improving the 'killing capacity' of neutrophils, an effect which persists for at least 6 hours of recovery. Given that neutrophils are the body's best phagocyte, these findings suggest that regular episodes of moderate exercise may increase resistance to infection.

In a randomised controlled study by Nieman et al. (1990) and Nehlsen-Cannarella et al. (1991), the effects of walking on immune response and acute respiratory infection tract symptomatology were measured on a group of sedentary, mildly obese women. The exercise subjects walked 45 minutes per session, 5 times per week, for 15 continuous weeks on a measured course under supervision. Subjects recorded health problems in a daily log book using 10 codes supplied by the Centers for Disease Control.

Exercise subjects experienced half the number of days with respiratory infection symptoms during the 15 weeks compared with the sedentary control group $(5.1 \pm 1.2$ vs $10.8 \pm 2.3$ days, respec- 
tively, $p=0.039$ ). The number of separate infectious episodes did not vary between groups $(1.0 \pm 0.2$ vs $1.1 \pm 0.2$ for exercise and sedentary groups, respectively, $p=0.693$ ) but the number of symptom days per infectious episode was significantly lower in the exercise group $(p=0.049)$ [fig. 3]. Moderate exercise training led to a $20 \%$ net increase in each of the 3 serum immunoglobulins, and was significantly correlated with fewer respiratory infection symptoms days (Nieman \& Nehlsen-Cannarella 1991b). Moderate exercise training also led to a significant increase in natural killer cell activity which was correlated with a decrease in the duration of respiratory infection symptoms per episode. These results are similar to those of Crist et al. (1989) who moderately exercised elderly women for 16 weeks and measured a $33 \%$ higher natural killer cell activity at rest, and a heightened increase following maximal testing.

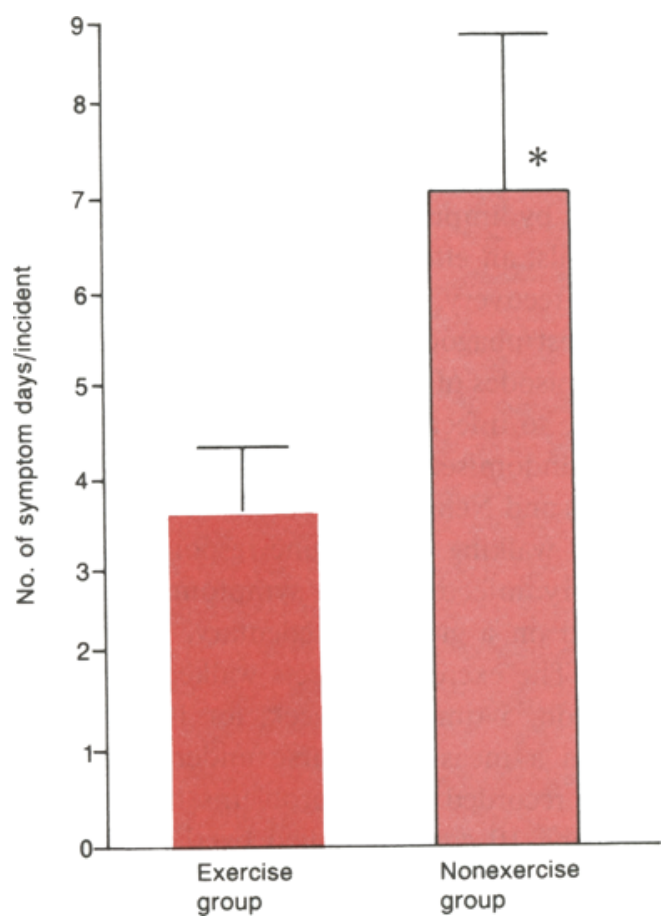

Fig. 3. Number of symptom days per upper respiratory tract infection incident in exercise and nonexercise groups $(*=p<0.05)$.
Thus, the response of the immune system to exercise may have much to do with the degree of intensity and total exertion load, and corresponding changes in concentrations of cortisol and epinephrine. Both of these hormones have been associated with many negative effects on immune function (Cavallo et al. 1986; Crary et al. 1983; Cupps \& Fauci 1982). Lymphocytes have $\beta$-adrenergic receptors, and the presence of epinephrine during exercise increases receptor number on $T$ suppressor/cytotoxic and natural killer cells, which are the major lymphocyte subsets that increase in response to an exercise challenge (Field et al. 1991; Maisel et al. 1990; Van Tits et al. 1990). The degree to which these lymphocyte subsets increase in the peripheral blood as they are recruited from lymphoid tissue pools is highly dependent on the magnitude of change in epinephrine. Additionally, the effect on lymphocyte function is also dependent on the change in both epinephrine and cortisol.

Moderate exercise such as walking does not increase the concentration of epinephrine and cortisol in the blood, resulting in a small lymphocytosis in contrast to intense exercise, in which levels of both hormones increase (Nieman 1991) [fig. 4]. Thus, it may be argued that moderate exercise induces a small increase in natural killer cells and $\mathrm{T}$ cytotoxic/suppressor cells without the potential suppressive effect of epinephrine or cortisol, creating a milieu which may be favourable for host protection. There is only a finite number of lymphocytes that is specific to any particular antigen. Theoretically, by recruiting lymphocytes from the periphery, exercise may increase the rate of lymphocyte circulation through the body, improving the potential for interaction of lymphocyte and antigen without the attending negative effects of stress hormones (Nieman \& Nehlsen-Cannarella 1992).

\section{Epidemiology of Exercise and Upper Respiratory Tract Infections}

Laboratory and clinical studies suggest that changes in immune parameters associated with heavy training lead to adverse health effects, par- 


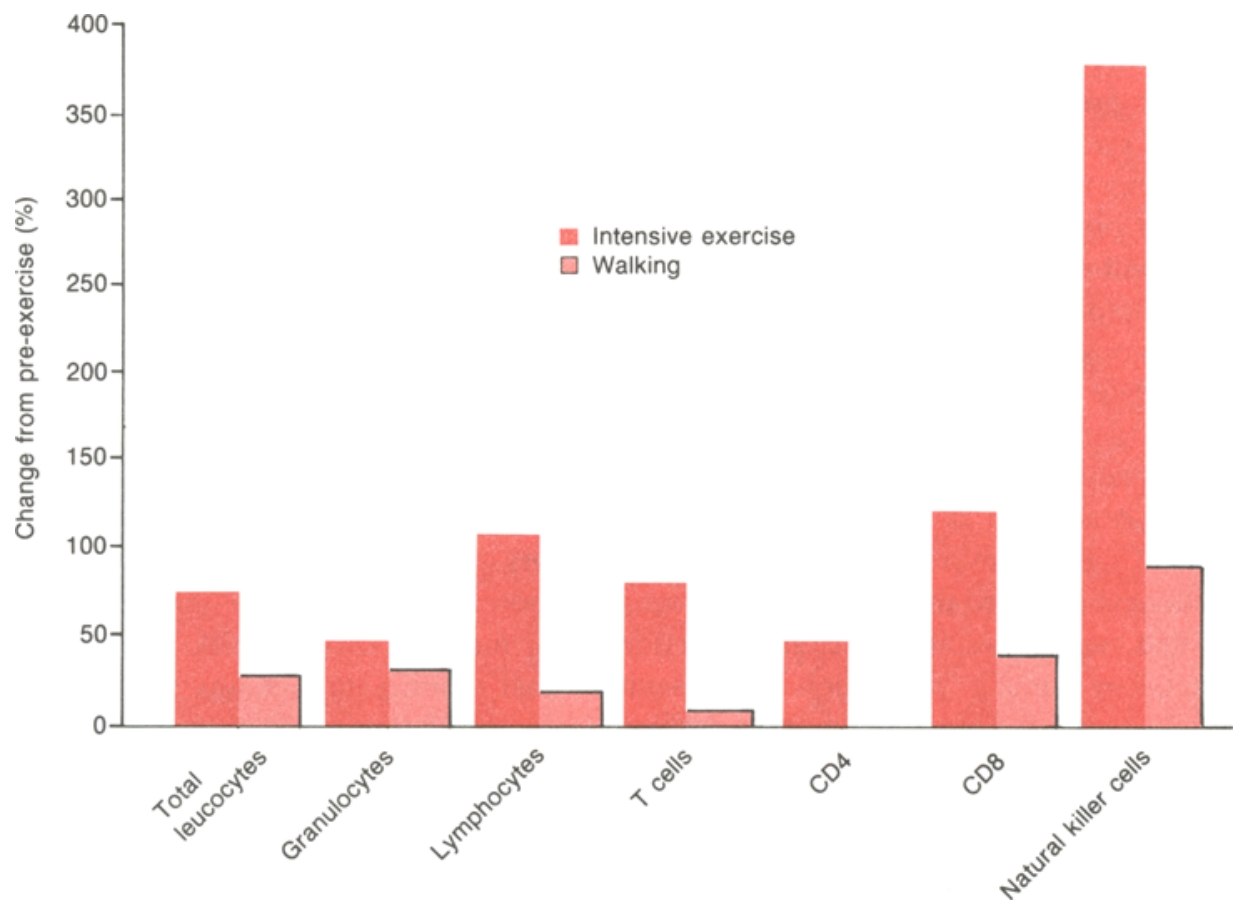

Fig. 4. Percentage change in selected immune markers in response to 2 acute exercise conditions: walking ( $\leqslant 70 \% \mathrm{\vee O}_{2 \max }$ ) and intensive exercise $\left(>70 \%\right.$ vे $\left._{2 \max }\right)$.

ticularly an increase in the incidence or severity of upper respiratory tract infections. However, anecdotal reports by marathon runners that running increased (or decreased) their incidence of upper respiratory tract infections were not correlated with immune system changes (Green et al. 1981). If the documented changes in immune parameters are associated with upper respiratory tract infections, there are several methods by which epidemiological investigations can be used to evaluate this effect.

To use the epidemiological approach, the following must be present: a defined population from which the exposed group and a comparison group can be selected, and a clear operational definition of the outcome of interest. The exposure (training) can be measured in a number of ways that would indicate relative levels of individual exertion. While this is not as accurate as the measurement that would occur in a laboratory setting, there is confidence that measuring levels of the exposure is possible in a population-based setting. However, defining the appropriate control or comparison group is a more difficult problem. Among studies involving runners, there have been a variety of methods used to determine the comparison group: faster runners were compared with slower runners of the same road race (Peters et al. 1983); low mileage runners were compared to high mileage runners over the same time period (Heath et al. 1991); marathon runners were compared with those who ran shorter races on the same day (Macera et al. 1991; Nieman et al. 1989c); marathon runners were compared with trained nonrunners (Nieman et al. $1990 \mathrm{~b}$ ), or marathon runners were compared with nonrunning friends (Peters et al. 1983). Each of these comparison groups has its advantages and drawbacks.

The true measure of the outcome (upper respiratory tract infections) is impossible to ascertain without a clinical examination and a laboratory workup. In lieu of a clinical assessment, the best 
surrogate measure for upper respiratory tract infection is self-reported symptoms. However, many other disease processes or allergic reactions may present with symptoms similar to those of upper respiratory tract infections. Unless these symptoms are severe or proceed to disability, most affected individuals will not be seen by medical personnel, and the symptoms will soon resolve without a medical diagnosis. In spite of these limitations, selfreport is the best choice, and steps can be taken to operationally define upper respiratory tract infection symptomatology so that definitions are consistent across studies.

In spite of these measurement difficulties, several studies have explored the relationship between exercise and upper respiratory tract infection symptomatology among population-based samples, usually runners. Among these studies, some have supported the suggestion that athletes engaging in marathon type events or very heavy training are at increased risk of respiratory tract infections (Heath et al. 1991; Nieman et al. 1990b; Peters et al. 1983), while others have found no difference among exposed and unexposed groups (Macera et al. 1991; Nieman et al. 1989c), and still others have found a decrease in infections among the exposed compared with the unexposed (Nieman et al. 1990a; Schouten et al. 1988).

Peters and Bateman (1983) studied the incidence of respiratory tract infections in 1550 randomly selected runners who took part in a $56 \mathrm{~km}$ race compared with matched controls who did not run. Those who ran the race reported more symptoms of respiratory tract infections during the 2week period following the race than those who did not run, and those who ran the faster race times reported more symptoms, indicating a doseresponse relationship.

Nieman et al. (1990b) studied the incidence of respiratory tract infection in a large group of marathon runners who varied widely in running ability and training habits. Those who ran the marathon reported more symptoms during the week following the race than similarly experienced runners who had applied but did not participate in the race for possible confounders, the researchers concluded that, compared with nonrunners, runners experience increased risk for respiratory tract infection during heavy training or following a marathon race event.

Heath et al. (1991) followed a cohort of 530 runners who self-reported any symptoms of respiratory infections daily for 1 year. The average runner was about 40 years of age, ran 20 miles $(32 \mathrm{~km})$ per week, and experienced a rate of 1.2 respiratory infections per year. Controlling for various confounding variables, the lowest odds ratio for respiratory infection was found among those running less than 10 miles $(16 \mathrm{~km})$ per week. The odds ratio more than doubled for those running more than 17 miles $(27 \mathrm{~km})$ per week. The authors concluded that running mileage was a significant risk factor for upper respiratory tract infection symptoms.

In another study, no difference (for either men or women) was found in the incidence of upper respiratory tract infection symptomatology during the month after the race for marathon runners compared with those who ran on the same day, but for shorter distances. In this study, the most important determinant for symptoms of upper respiratory tract infection after the race was the presence of upper respiratory tract infection symptoms before the race. These results persisted after controlling for total training mileage and percentage increase in training mileage during the month before the race.

Nieman et al. (1989c) studied the incidence of upper respiratory tract infection symptoms among participants in $5 \mathrm{~km}, 10 \mathrm{~km}$ and half-marathon road races. During the 2 months before the race, those running more than 15 miles $(24 \mathrm{~km})$ per week reported more events than those running fewer miles. There was no increase in symptoms after the road race compared with the week before the road race, indicating that the race did not appear to be associated with an increased risk of acute upper respiratory tract infection.

In a study of young adults, Schouten et al. (1988) found no difference in the incidence or duration of upper respiratory tract infection symptoms when 
level of sports activity or maximum aerobic power. They found a slight inverse association between symptoms and level of sports activity for women only. Although this study had the advantage of measuring several types of physical activity as well as aerobic power, the upper respiratory tract infection measurement relied on memory recall for the past 6 months, leading to possible misclassification.

In a 15-week study of immune response and exercise, 36 mildly obese women were randomly assigned to walking or nonexercising groups (Nieman et al. 1990a). During this time, the women in the exercise group experienced fewer upper respiratory tract infection symptom days, improved cardiorespiratory fitness, and increased natural killer cell numbers compared with their sedentary controls. This study indicates that intensity of exercise may play a role, and that moderate activity may actually improve immune function and associated upper respiratory tract infection symptoms.

Because this is a new field it is not surprising that the results of the few studies done to date have not been consistent. While most, but not all, of the published studies have found a relationship between increased training and upper respiratory tract infections, and considering that the type and intensity of exercise has not been fully explored, no definitive conclusions can be drawn. However, on the basis of the available studies, some general guidelines can be provided for future studies.

Separate comparison groups, a lower intensity running or exercise comparison group as well as a nonexercising or sedentary comparison group should be considered. During the analysis stage the comparison groups could be used to sort out some of the biases present in the previous studies.

Because reporting behaviour differs between men and women, the sample size should be large enough to allow separate analyses for men and women. A consistent time frame for reporting upper respiratory tract infection symptoms after racing events should be used. The studies noted here have used follow-up times ranging from 1 to 4 weeks. When using self-report data, every attempt should be made to differentiate symptoms due to allergy from symptoms because of upper respiratory tract infections. Because allergic rhinitis may be present (but undiagnosed) the case definition of upper respiratory tract infections should be defined in such a way as to capture most of the events. Data should also be collected on duration of the event, and for longer studies, the number of symptom-free days between events should be defined.

\section{Guidelines for the Athlete and the Exercising Public}

At present, insufficient evidence exists to recommend precisely what laboratory tests of immune function should be conducted to ascertain when an athlete is at increased risk of an infectious episode due to overtraining and/or psychosocial stress. Although some evidence would suggest that low immunoglobulin and complement levels, decreased lymphocyte proliferative response, diminished neutrophil phagocytic activity, depressed natural killer cell activity, low total lymphocyte count and low helper/suppressor $T$ cell ratio are each important markers of increased risk, the exact level at which one or a combination of some or all of these immune components becomes predictive is unknown (Nieman \& Nehlsen-Cannarella 1992).

There is an interesting similarity in the metabolic and immunological responses to intense endurance exercise and to an infectious challenge (Lewis et al. 1986; Schaefer et al. 1987). In both conditions, the number of circulating leucocytes increases, lymphopenia occurs (especially $\mathrm{T}$ cells with cells trafficking to peripheral tissues), the lymphocyte responses to phytohaemagglutinin (PHA) and concanavalin (Con-A) decrease, body core temperature rises, plasma levels of acute phase proteins increase and degranulation of neutrophils develops. Since endurance exercise is associated with muscle cell damage and an increased intake of potential pathogens through heightened ventilation, it is logical that in preparation for such a challenge, the immune system receives a signal from the neuroendocrine network that activates the immune system. 
Why then do clinical experience and epidemiological data point toward an increased risk of respiratory infection in some athletes? The mass of evidence favours the view that psychosocial variables play an important role in effecting immunological competence. The net effect of combined psychological and physiological stress from unusually heavy endurance exercise, especially during times of competition, may lead to suppression or down-regulation of the immune system.

For those athletes who must exercise intensely for competitive reasons, several precautions can help decrease the risk of sickness. These include spacing vigorous workouts and race events as far apart as possible, eating a well balanced diet, keeping other life stresses to a minimum, avoiding overtraining and chronic fatigue and obtaining adequate sleep. Before and after intense race events, the athlete should try to avoid contact with sick people if at all possible.

For the fitness enthusiast, the area of concern is not so much the harm that may come from overexertion, but the benefits that may derive from engaging in regular, moderate forms of exercise. At this time, even though investigative evidence suggests improved host protection and immunosurveillance from moderate physical activity, more research is needed to improve our understanding of the workload threshold below or above which exercise becomes protective rather than detrimental.

Should athletes exercise when they have an upper respiratory tract infection? Most clinical authorities in this area recommend that if the athlete has symptoms of a common cold with no constitutional involvement, then regular training may be safely resumed a few days after the resolution of symptoms (Roberts 1986; Simon 1987). Mild exercise during sickness with the common cold does not appear to be contraindicated. However, if there are symptoms or signs of systemic involvement (e.g. fever, extreme fatigue, muscle aches, swollen lymph glands), then 2 to 4 weeks should be allowed before resumption of more intense training. These precautions are advised because of the well documented relationship between intense exercise and the risk of developing a viral cardiomyopathy and other severe form of viral infection (Sharp 1989).

\section{Conclusions}

Physical activity and exercise produce a variety of alterations of the immune system, most of which have not been fully investigated. However, the effects of vigorous exercise appear to depress immune function and may compromise host defense against upper respiratory tract infections. Because of the complexity of host defence mechanisms and the physiology of exercise, further research is needed in this area. Clinical studies examining the effects of moderate levels of physical activity have shown possible enhanced immune responses with a concomitant impact on the length and severity of an upper respiratory tract infection. Therefore, the relationship between exercise and upper respiratory tract infections appears to be ' $J$ ' shaped with the most sedentary at greatest risk of upper respiratory tract infections along with the vigorously active, with those engaged in moderate levels of activity manifesting the apparently better host defence.

Epidemiological studies have generally demonstrated a greater risk of upper respiratory tract infection with vigorous levels of exercise; however, these studies must be considered to be limited because of the lack of adequate nonexercising control groups. Further studies are necessary to demonstrate the clinical and public health significance of these relationships.

Engaging in regular moderate level physical activity is most beneficial for maintaining health and in preventing an initial upper respiratory tract infection. Moderate level physical activity coupled with generally good hygiene and avoidance of close contact with individuals known to have an active upper respiratory tract infection appear to be the most commonsense measures for avoiding contracting an upper respiratory tract infection. However, since avoidance of a high risk situation, such as the presence of children, is often difficult, the hygienic measures of frequent handwashing and the thorough washing of potential fomitic surfaces will aid in reducing exposure to the upper respiratory 
tract infection agent. For those athletes who are required to engage in high intensity training and competition, further steps should be taken to minimise contact with situations where exposure to upper respiratory tract infection agents is high. In addition, training techniques should take into con: sideration the need for the organism to restore host resistance by including lower intensity training sandwiched between higher intensity training bouts.

\section{References}

Badger GF, Dingle JH, Feller AE. A study of illness in a group of Cleveland families: II. Incidence of common respiratory diseases. American Journal of Hygiene 58: 41-46, 1953

Berk LS, Nieman DC, Youngberg WS, Arabatais K, SimpsonLuesterberg $M$. The effect of long endurance running on natural killer cells in marathoners. Medicine and Science in Sports and Exercise 22: 207-212, 1990

Blalock JE. A molecular basis for bidirectional communication between the immune and neuroendocrine systems. Physiological Reviews 69: 1-32, 1989

Blumenthal JA, Williams RB, Wallace AG. Effects of exercise on the Type A (coronary prone) behaviour pattern. Psychosomatic Medicine 42: 289-296, 1980

Brimblecombe FSW, Cruickshank R, Masters PL, Reid DD. Family studies of respiratory infections. British Medical Journal 1: $119-128,1958$

Cannon JG, Kluger JJ. Exercise enhances survival rate in mice infected with Salmonella typhimurium. Proceedings of the Society for Experimental Biology and Medicine 175: 518-521, 1984

Cavallo R, Dartori ML, Gatti G, Angeli A. Cortisol and immune interferon can interact in the modulation of human natural killer cell activity. Experientia 42: 177-179, 1986

Cohen S, Tyrrell DA, Smith AP. Psychological stress and susceptibility to the common cold. New England Journal of Medicine 325: 606-612, 1991

Coulehan JJ, Eberhard S, Kapner L, Taylor F, Rogers K, et al. Vitamin $C$ and acute illness in Navajo school children. New England Journal of Medicine 18: 973-977, 1976

Crary B, Hauser SL, Borysenko M, Kutz L, Hoban C et al. Epinephrine-induced changes in the distribution of lymphocyte subsets in peripheral blood of humans. Journal of Immunology 131: 1178-1181, 1983

Crist DM, Mackinnon LT, Thompson RF, Atterbom HA, Egan PA. Physical exercise increases natural cellular-mediated tumor cytotoxicity in elderly women. Gerontology 35: 66-71, 1989

Cupps TR, Fauci AS. Corticosteroid-mediated immunoregulation in man. Immunological Review 65: 133-155, 1982

Dingle JH, Badger GF, Jordan Jr WS. Illness in the home: study of 25000 illnesses in a group of Cleveland families, Chapter 1, pp. 1-3, Press of Western Reserve University, Cleveland, 1964

Douglas Jr RG, Lindgren KM, Couch RB. Exposure to cold environment and rhinovirus common cold: failure to demonstrate effect. New England Journal of Medicine 279: 743-747, 1968

Dufaux B, Order U. Complement activation after prolonged exercise. Clinical Chimica Acta 179:45-49, 1989a

Dufaux B, Order U. Plasma elastase-alpha 1-antitrypsin, neopterin, tumor necrosis factor, and soluble interleukin-2 receptor after prolonged exercise. International Journal of Sports Medicine 10: 434-438, 1989b
Eskola J, Ruuskanen O, Soppi E,Viljanen K, Järvinen M et al. Effect of sport stress on lymphocyte transformation and antibody formation. Clinical and Experimental Immunology 32: 339-345, 1978

Evans WJ, Cannon JG. The metabolic effects of exercise-induced muscle damage. Exercise and Sport Sciences Reviews 19: 99125,1991

Ferry A, Weill BL, Rieu M. Immunomodulations induced in rats by exercise on a treadmill. Journal of Applied Physiology 69: 1912-1915, 1990

Field CJ, Gougeon R, Marliss EB. Circulating mononuclear cell numbers and function during intense exercise and recovery. Journal of Applied Physiology 71: 1089-1097, 1991

Fox JP, Hall CE, Cooney MK, Luce RE, Kronmal RA. The Seattle virus watch: II. Objectives. Study population and its observation data processing and summary of illnesses. American Journal of Epidemiology 96: 270-285, 1972

Gmander FK, Lorenzi G, Bechler B, Joller P, Muller J et al. Effect of long-term physical exercise on lymphocyte reactivity: similarity to spaceflight reactions. Aviation, Space and Environmental Medicine 59: 146-151, 1988

Graham NMH, Douglas RM, Ryan P. Stress and acute respiratory infection. American Journal of Epidemiology 124: 389401,1986

Green RL, Kaplan SS, Rabin BS, Stanitski CL, Zdziarski U. Immune function in marathon runners. Annals of Allergy 47: 7375,1981

Gwaltney Jr JM, Hendley JO. Rhinovirus transmission, one if by air, two if by hand. American Journal of Epidemiology 107: 357-361, 1978

Gwaltney Jr JM. Rhinovirus colds: epidemiology, clinical characteristics and transmission. European Journal of Respiratory Diseases 64 (Suppl. 128): 336-339, 1983

Gwaltney Jr JM, Hendley JO, Simon G, Jordan Jr WS. Rhinovirus infections in an industrial population: 1 . The occurrence of illness. New England Journal of Medicine 275: 1261-1268, 1966

Gwaltney Jr JM, Hendley JO, Simon G, Jordan Jr WS. Rhinovirus infections in an industrial population: II. Characteristics of illness and antibody response. Journal of the American Medical Association 202: 494-500, 1967

Hall CB, McBride JT. Upper respiratory tract infections: the common cold, pharyngitis, croup, bacterial tracheitis and epiglottitis. In Pennington (Ed.) Respiratory infections: diagnosis and management, pp. 97-118, Raven Press, New York, 1989

Heath GW, Ford ES, Craven TE, Macera CA, Jackson KL, et al. Exercise and the incidence of upper respiratory tract infections. Medicine and Science in Sports and Exercise 23: 152157,1991

Heath GW, Hagberg JM, Ehsani AA, Holloszy JO. A physiological comparison of young and older endurance athletes. Journal of Applied Physiology 51: 634-640, 1981

Hendley JO, Wentzel RP, Gwaltney Jr JM. Transmission of rhinovirus colds by self-inoculation. New England Journal of Medicine 288: 1361-1364, 1973

Hughes JR. Psychological effects of habitual aerobic exercise: a critical review. Preventive Medicine 13: 66-78, 1984

Hoffman-Goetz L, Keir R, Thorne R, Houston ME, Young C. Chronic exercise stress in mice depresses splenic $T$ lymphocyte mitogenesis in vitro. Clinical and Experimental Immunology 66: 551-557, 1986

Israel S, Buhl B, Krause M, Neumann G. Die Konzentration der Immunglobuline $A, G$ und $M$ im Serum bei Trainierten und Untrainierten sowie nach verschiedenen sportlichen Ausdauerleistungen. Medizin und Sport 22: 225-231, 1982

Jemmott JB, Locke SE. Psychosocial factors, immunologic mediation, and human susceptibility to infectious diseases: how much do we know? Psychological Bulletin 95: 78-108, 1984

Kappel M, Tvede N, Galbo H, Haahr PM, Kjaer M et al. Evi- 
dence that the effect of physical exercise on NK cell activity is mediated by epinephrine. Journal of Applied Physiology 70: 2530-2534, 1991

Karlowski TR, Chalmers TC, Frenkel LD, Kapikian AZ, Lewis TL, et al. Ascorbic acid for the common cold: a prophylactic and therapeutic trial. Journal of the American Medical Association 231: 1038-1042, 1975

Khansari DN, Murgo AJ, Faith RE. Effects of stress on the immune system. Immunology Today 11: 170-175, 1990

Lewis DE, Gilbert BE, Knight V. Influenza virus infection induces functional alterations in peripheral blood lymphocytes. Journal of Immunology 137: 3777-3781, 1986

Linde F. Running and upper respiratory tract infections. Scandinavian Journal of Sports Sciences 9: 21-23, 1987

Macera CA, Pate RR, Davis DR, Jackson KL, Woods J. Postrace morbidity among runners. American Journal of Preventive Medicine 7: 1-5, 1991

Mackinnon LT, Chick TW, van As A, Tomasi TB. The effect of exercise on secretory and natural immunity. Advances in Experimental Medicine and Biology 216A: 869-876, 1987

MacNeil B, Hoffman-Goetz L, Kendall A, Houston M, Arumugam Y. Lymphocyte proliferation response after exercise in men: fitness, intensity, and duration effects. Journal of Applied Physiology 70: 179-185, 1991

Mahan MP, Young MR. Immune parameters of untrained or exercise-trained rats after exhaustive exercise. Journal of Applied Physiology 66: 282-287, 1989

Maisel AS, Harris T, Rearden CA, Michel MC. B-Adrenergic receptors in lymphocyte subsets after exercise: alterations in normal individuals and patients with congestive heart failure. Circulation 82: 2003-2010, 1990

Miller JZ, Nance WE, Norton JA, Wolen RL, Griffith RS, et al. Therapeutic effect of vitamin C: a co-twin control study. Journal of the American Medical Association 237: 248-251, 1977

Naliboff BD, Benton D, Solomon GF, Morley JE, Fahey JL, et al. Immunological changes in young and old adults during brief laboratory stress. Psychosomatic Medicine 53: 121-132, 1991

Nash HL. Can exercise make use immune to disease? Physician and Sportsmedicine 14: 250-253, 1986

Nehlsen-Cannarella SL, Nieman DC, Balk-Lamberton AJ, Markoff PA, Chritton DB et al. The effects of moderate exercise training on immune response. Medicine and Science in Sports and Exercise 23: 64-70, 1991

Nieman DC, Berk LS, Simpson-Westerberg M, Arabatzis K, Youngberg $S$ et al. Effects of long endurance running on immune system parameters and lymphocyte function in experienced marathoners. International Journal of Sports Medicine 10: 317-323, 1989a

Nieman DC, Nehlsen-Cannarella SL. Effects of endurance exercise on immune response. In Shephard \& Astrand (Eds) Endurance in sport, Blackwell Scientific Publications, Oxford, 1991a

Nieman DC, Nehlsen-Cannarella SL. The effects of acute and chronic exercise on immunoglobulins. Sports Medicine 11: 183201, 1991b

Nieman DC, Nehlsen-Cannarella SL. Exercise and infection. In Eisinger \& Watson (Eds) Exercise and disease, CRC Press, Inc., Boca Raton, in press, 1992

Nieman DC, Nehlsen-Cannarella SL, Donohue KM, Chritton DB, Haddock BL et al. The effects of acute moderate exercise on leucocyte and lymphocyte subpopulations. Medicine and Science in Sports and Exercise 23: 578-585, 1991c

Nieman DC, Nehlsen-Cannarella SL, Markoff PA, Balk-Lamberton $\mathrm{AJ}$, Yang $\mathrm{H}$ et al. The effects of moderate exercise training on natural killer cells and acute upper respiratory tract infections. International Journal of Sports Medicine 11: 467-473, 1990a

Nieman DC, Tan SA, Lee JW, Berk LS. Complement and im- munoglobulin levels in athletes and sedentary controls. International Journal of Sports Medicine 10: 124-128, 1989b

Nieman DC, Johanssen LM, Lee JW. Infectious episodes in runners before and after a roadrace. Journal of Sports Medicine 29: $289-296,1989$ c

Nieman DC, Johanssen, Lee JW, Arabatzis K. Infectious episodes in runners before and after the Los Angeles Marathon. Journal of Sports Medicine and Physical Fitness 30: 316-328, 1990b

Osterback L, Qvarnberg Y. A prospective study of respiratory infections in 12-year-old children actively engaged in sports. Acta Paediatrica Scandinavica 76: 944-949, 1987

Paffenbarger RS, Hyde RT, Wing AL, Hsieh CC. Physical activity, all cause mortality, and longevity of college alumni. New England Journal of Medicine 314: 605-613, 1986

Pedersen BK, Tvede N, Christensen LD, Christensen LD, Klarlund $\mathrm{K}$ et al. Natural killer cell activity in peripheral blood of highly trained and untrained persons. International Journal of Sports Medicine 10: 129-131, 1989

Pedersen BK, Tvede N, Hansen FR, Anderson V, Bendix $T$ et al. Modulation of natural killer cell activity in peripheral blood by physical exercise. Scandinavian Journal of Immunology 27 : 673-678, 1988

Pedersen BK, Tvede N, Klarlund K, Christensen LD, Hansen FL et al. Indomethacin in vitro and in vivo abolishes post-exercise suppression of natural killer cell activity in peripheral blood. International Journal of Sports Medicine 11: 127-131, 1990

Pershin BB, Kuz'min SN, Suzdal'nitskii RS, Levando VA. Reserve potentials of immunity. Zhurnal Mikrobiologii Epidemiologii Immunobiologii 6: 59-64, 1985

Peters EM, Bateman ED. Ultramarathon running and upper respiratory tract infections. South African Medical Journal 64: $582-584,1983$

Petrova IV, Kuz'min SN, Kurshakova TS, Suzdail'nitskii RS, Levando VA. The phenomenon of the formation of universal rosette-forming cells under superextreme loads. Zhurnal Mikrobiologii Epidemiologii Immunobiologii 2: 72-76, 1985

Petrova IV, Kuz'min SN, Kurshakova TS, Suzdail'nitskii RS, Pershin BB. Neutrophil phagocytic activity and the humoral factors of general and local immunity under intensive physical loading. Zhurnal Mikrobiologii Epidemiologii Immunobiologii 12: 53-57, 1983

Powell KE, Thompson PD, Caspersen CJ, Kendrick JS. Physical activity and the incidence of coronary heart disease. Annual Review of Public Health 8: 253-287, 1987

Roberts JA. Viral illnesses and sports performance. Sports Medicine 3: 296-303, 1986

Schaefer RM, Kokot K, Heidland A, Plass R. Jogger's leukocytes. New England Journal of Medicine 316: 223-224, 1987

Schouten WJ, Verschuur R, Kemper HCG. Physical activity and upper respiratory tract infections in a normal population of young men and women: the Amsterdam growth and health study. International Journal of Sports Medicine 9: 451-455, 1988

Sharp JCM. Viruses and the athlete. British Journal of Sports Medicine 23: 47-48, 1989

Simpson JR, Hoffman-Goetz L. Exercise stress and murine natural killer cell function. Proceedings of the Society for Experimental Biology and Medicine 195: 129-135, 1990

Simon B. Exercise and infection. Physician and Sportsmedicine 15: 135-141, 1987

Sinyor D, Schwartz SG, Peronnet F, Brisson G, Serganian P et al. Aerobic fitness level and reactivity to psychosocial stress: physiological, biochemical, and subjective measures. Psychosomatic Medicine 45: 205-217, 1983

Slubik VM, Levin MI, Mashneva NI, Pulkov VM. The combined effect of ionizing radiation and physical exercises on some indices of nonspecific protection and immunity. Radiobiologiia 27: 548-550, 1987

Smith JA, Telford RD, Mason IB, Weidemann MJ. Exercise, 
training and neutrophil microbicidal activity. International Journal of Sports Medicine 11: 179-187, 1990

Smith JK, Chi DS, Krish G, Reynolds S, Cambron G. Effect of exercise on complement activity. Annals of Allergy 65: 304310,1990

Smith LL. Acute inflammation: the underlying mechanism in delayed onset muscle soreness? Medicine and Science in Sports and Exercise 23: 542-551, 1991

Tomasi TB, Trudeau FB, Czerwinski D, Erredge S. Immune parameters in athletes before and after strenuous exercise. Journal of Clinical Immunology 2: 173-178, 1982

Tvede N, Heilmann C, Halkjaer-Kristensen J, Pedersen BK. Mechanisms of B-lymphocyte suppression induced by acute physical exercise. Journal of Clinical and Laboratory Immunology 30: 169-173, 1989

Van Tits LJ, Michel MC, Grosse-Wilde H, Happel M, Eigler FW et al. Catecholamines increase lymphocyte beta 2 -adrenergic receptors via a beta 2-adrenergic, spleen-dependent process. American Journal of Physiology 258: E191-202, 1990

Correspondence and reprints: Dr Gregory W. Heath, Division of Chronic Disease Control and Community Intervention, MS-K47, Centers for Disease Control, 4770 Buford Highway NE, Atlanta, GA 30341-3724, USA.

\section{Second Maccabiah - Wingate International Congress on Sport Sciences and Coaching \\ Date: 30 June-4 July, 1993 Venue: Netanya, Israel}

For further information, please contact: Hony Tenenbaum International Congress

Wingate Institute for Physical Education and Sport

Wingate Post Office

Netanya, 42902

ISRAEL 